\title{
Uncatalyzed urethane forming reaction of 1,3-xylylene diisocyanate with aliphatic alcohols of varying chain lengths and polyols
}

\author{
L. Nagy' ${ }^{1}$ A. Juhász ${ }^{1,2}$, M. Zsuga 1 , S. Kéki ${ }^{1^{*}}$ \\ ${ }^{1}$ Department of Applied Chemistry, Faculty of Science and Technology, University of Debrecen, Egyetem tér 1, \\ H-4032 Debrecen, Hungary \\ ${ }^{2}$ BorsodChem Zrt, Bolyai tér 1., H-3700 Kazincbarcika, Hungary
}

Received 23 August 2019; accepted in revised form 3 November 2019

\begin{abstract}
In this article, we report a detailed study on the kinetics of the reaction of 1,3-xylylene diisocyanate (1,3-XDI) with alcohols of varying alkyl chain lengths and with low molecular weight polyols such as monomethoxylated polyethylene glycol (mPEG) and polytetrahydrofuran (PTHF) in toluene, in the absence of a catalyst. It was found that the pseudo-firstorder rate coefficient increased with the increasing alkyl chain length $\left(k_{1, \text { app }}\right.$ was found to be 0.0166 and $0.0341 \mathrm{~min}^{-1}$ for 1-propanol and 1-hexanol, respectively) and the reactivities of the 1,3-xylyene diisocyanate towards the alcohols and polyols are between those of the aromatic and alkyl isocyanates. The activation energies were also determined and were found to vary from 25.6 to $38.6 \mathrm{~kJ} / \mathrm{mol}$ (from 1-propanol to 1-hexanol). According to further kinetic studies, the rate coefficients $k_{1 \text {,app }}$ and $k_{2 \text {,app }}$ for the reaction of 1,3-XDI with PTHF were determined to be $(1.13 \pm 0.01) \cdot 10^{-2}$ and $(1.28 \pm 0.01) \cdot 10^{-2} \mathrm{~min}^{-1}$, respectively. It was also found that the rate constants did not depend significantly on the length of the polymer chain. However, significantly lower rate coefficients were obtained for the 1,3 -XDI-mPEG reaction $\left(k_{1, \text { app }}=(2.64 \pm 0.03) \cdot 10^{-3} \mathrm{~min}^{-1}\right.$ and $\left.k_{2 \text {,app }}=(2.45 \pm 0.03) \cdot 10^{-3} \mathrm{~min}^{-1}\right)$. Besides, the dependence of the pseudo-first-order rate coefficient on the concentration of the alcohols was also studied, and based on these findings a reaction mechanism is proposed.
\end{abstract}

Keywords: polymer synthesis, molecular engineering, xylylene diisocyanate, kinetics, aliphatic alcohols

\section{Introduction}

In recent years, polyurethane-based (PU) products have been receiving increasing interest in various areas spanning from automotive systems [1] through the construction industry [2] to various biomedical applications [3, 4]. PUs can also be used as functional substances such as high-performance 'smart' materials e.g. with shape-memory $[5,6]$ and/or self-healing properties [7].

The manufacturing of PUs is based on a simple nucleophilic addition reaction taking place between diisocyanates and polyether- or polyester-based polyols $[8,9]$. The properties of the resulting PU-product can be modified and tailor-made by proper selection of the raw materials i.e., by varying the isocyanate and the polyols components [9]. For instance, PUs based on aliphatic isocyanates have higher UV stability than that of the PUs produced using aromatic isocyanates. Furthermore, linear and cross-linked polymers can be obtained by varying the functionality of the reagents and applying crosslinking agents $[8,9]$. It is well-known that most of the PU-based goods are produced from aromatic isocyanates such as 4,4'diphenylmethane-diisocyanate (MDI) or toluenediisocyanate (TDI) $[8,9]$. However, PUs based on MDI or TDI possess poor light stability, and they 
often tend to show coloration upon aging and/or upon the effect of irradiation [10]. In contrast, aliphatic or cycloaliphatic diisocyanates such as hexamethylene diisocyanate (HDI) or dicyclohexyl diisocyanate (HMDI) reveal good resistance to light, and at the same time they impart softer mechanical characteristics to the product made based on aliphatic raw materials $[8,9]$. As the properties of the PU-product strongly depend on the isocyanate component it is evident that application of other type isocyanates may have advantageous effects on the behavior of the products. Among the diisocyanates employed in the polyurethane industry, benzyl type isocyanates, including 1,3-xylylene (1,3-XDI or meta-XDI) or 1,4xylylene diisocyanates (1,4-XDI or para-XDI) [1113] represent very interesting and promising candidates since the properties of products made from them as well as their reactivities towards alcohols are expected to be between those of the aromatic and the aliphatic ones. Indeed, these diisocyanates have been gaining increasing industrial attention. For example, the Mitsuo Chemicals Inc. has launched its new state-of-the-art XDI plant in 2016 for production of high-performance PUs such as high-quality coatings and high-refractive-index ophthalmic lens [14]. Therefore, from both scientific and industrial points of view, it is essential to learn more about the kinetics and the mechanism of the reaction taking place between XDI and various alcohols and polyols. The number of reports on the kinetic study of the XDI-alcohol or XDI-polyol reactions is minimal $[15,16]$. However, the kinetic data reported in these and other works can not be at all or complicated to compare directly to those obtained for the reactions of MDI, TDI, or aliphatic diisocyanates with various alcohols and polyols due to the different reaction conditions.

Therefore, in this report, we focused our attention on the reaction of 1,3-XDI with aliphatic alcohols of different alkyl chain length and polyols such as metoxylated polyethylene glycol (mPEG) and polytetrahydrofuran (PTHF). In this work, the following tasks were performed: (i) The effect of the length of the alkyl chain of primary alcohols on the reaction rate coefficient. (ii) The reactivity of 1,3-XDI towards alcohols and polyols, especially concerning those of MDI and TDI (To obtain comparable kinetic data, the same reaction conditions were used in this study as those applied for other diisocyanate-alcohol reactions $[17,18]$ ). (iii) Prediction of the product distribution in the 1,3-XDI-polyol reactions using the kinetic data obtained in the reaction of 1,3-XDI with alcohol mimicking the chain-end of the given polyol. (iv) An additional goal was to determine and evaluate the activation parameters of 1,3-XDI versus alcohol reactions. Since the 1,3-XDI-alcohol reactions were performed under the same experimental conditions as for the MDI and TDI systems, direct comparison with the previous MDI and TDI data is feasible.

\section{Experimental section}

\subsection{Materials}

For the kinetic measurements 1,3-xylylene diisocyanate (1,3-XDI) (Sigma-Aldrich, Darmstadt, Germany) and anhydrous aliphatic alcohols with varying chain lengths such as 1-propanol, 1-butanol, 1-pentanol and 1-hexanol from Sigma-Aldrich (Darmstadt, Germany) were used fresh, as received. Polyols including diethylene glycol monomethylether (DEGME), metoxylated polyethylene glycol (mPEG) $\left(M_{\mathrm{n}}=750 \mathrm{~g} / \mathrm{mol}\right)$ and polytetrahydrofuran (PTHF) $\left(M_{\mathrm{n}}=250 \mathrm{~g} / \mathrm{mol}\right)$ were also purchased from SigmaAldrich (Darmstadt, Germany) and used fresh, as received. The anhydrous methanol (analytical grade) and toluene (analytical grade) were obtained from VWR (Leuven, Belgium). Toluene was distilled over $\mathrm{P}_{2} \mathrm{O}_{5}$ and before use, it was stored on sodium wire.

\subsection{Description of the procedure for the reactions of 1,3-XDI with alcohols and polyols}

Into a flask thermostated between 50 and $80^{\circ} \mathrm{C}$, dry toluene $(5 \mathrm{~mL})$ and the calculated amount of $1,3-\mathrm{XDI}$ were added under nitrogen atmosphere. After addition of the predetermined amount of the corresponding alcohol or polyol, the reaction mixture was further diluted with dry toluene to attain a reaction volume of $10 \mathrm{~mL}$. The concentrations of the 1,3-XDI and the alcohols or polyol in the reaction mixture were 0.01 and $0.65 \mathrm{M}$, respectively. At appropriate times, $20 \mu \mathrm{L}$ of samples were withdrawn from the reaction mixture and quenched in methanol of $980 \mu \mathrm{L}$.

\subsection{Monitoring the reaction using high-performance liquid chromatography (HPLC)}

$10 \mu \mathrm{L}$ samples from the solution described in section 2.2. were introduced into the chromatographic system consisting of a Waters 2695 Separations Module with a thermostable autosampler $\left(5^{\circ} \mathrm{C}\right)$ and a column 
module $\left(40^{\circ} \mathrm{C}\right)$, a VDSphere PUR $100 \mathrm{C} 18$-M-SE reverse phase $\mathrm{C}-18$ column $(4.6 \times 150 \mathrm{~mm}, 5 \mu \mathrm{m})$ (VDS Optilab Chromatographie Technik GmbH, Berlin, Germany) and a Waters 2996 Photodiodearray detector (PDA). The analytes were detected with PDA detector at $\lambda=210 \mathrm{~nm}$, and the flow rate was $1.0 \mathrm{~mL} / \mathrm{min}$ in all cases.

For the quantifications of the products gradient HPLC methods composed of methanol and water were used as eluents. The applied gradient data for the separations are compiled in Table 1.

For the separations of urethane products formed with 1-propanol and 1-butanol gradient A was used, while for those with 1-pentanol gradient B, with 1-hexanol gradient $\mathrm{C}$, with DEGME, $\mathrm{PPEG}$ and PTHF gradient $\mathrm{D}$, gradient $\mathrm{E}$ and gradient $\mathrm{F}$ were applied, respectively.

\subsection{Assessment of the kinetic data}

The main reaction steps between 1,3-XDI and alcohols and polyols are shown in Figure 1. Note that after predetermined intervals, the reactions were quenched with methanol (i.e., the unreacted isocyanate groups were reacted). The products of the methanol-quenched reactions are denoted as XDI_1,3, XDI_1,3R, and XDI_1R,3R.

Table 1. Gradient table data for the HPLC separations of the reaction products.

\begin{tabular}{|c|c|c|c|c|c|c|c|c|}
\hline \multicolumn{3}{|c|}{ Gradient A } & \multicolumn{3}{|c|}{ Gradient B } & \multicolumn{3}{|c|}{ Gradient C } \\
\hline $\begin{array}{l}\text { Time } \\
\text { [min] }\end{array}$ & $\begin{array}{c}\mathrm{MeOH} \\
{[\%]}\end{array}$ & $\begin{array}{l}\mathrm{H}_{2} \mathrm{O} \\
{[\%]}\end{array}$ & $\begin{array}{l}\text { Time } \\
\text { [min] }\end{array}$ & $\begin{array}{c}\mathrm{MeOH} \\
{[\%]}\end{array}$ & $\begin{array}{l}\mathrm{H}_{2} \mathbf{O} \\
{[\%]}\end{array}$ & $\begin{array}{l}\text { Time } \\
\text { [min] }\end{array}$ & $\begin{array}{c}\mathrm{MeOH} \\
{[\%]}\end{array}$ & $\begin{array}{l}\mathrm{H}_{2} \mathrm{O} \\
{[\%]}\end{array}$ \\
\hline 0.00 & 50.0 & 50.0 & 0.00 & 50.0 & 50.0 & 0.00 & 50.0 & 50.0 \\
\hline 4.00 & 50.0 & 50.0 & 4.00 & 50.0 & 50.0 & 4.00 & 50.0 & 50.0 \\
\hline 16.00 & 60.0 & 40.0 & 4.10 & 60.0 & 40.0 & 40.00 & 80.0 & 20.0 \\
\hline \multirow[t]{3}{*}{29.00} & 60.0 & 40.0 & 15.00 & 60.0 & 40.0 & 43.00 & 80.0 & 20.0 \\
\hline & & & 25.00 & 80.0 & 20.0 & & & \\
\hline & & & 27.00 & 80.0 & 20.0 & & & \\
\hline \multicolumn{3}{|c|}{ "Gradient D } & \multicolumn{3}{|c|}{ 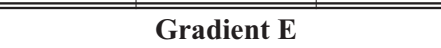 } & \multicolumn{3}{|c|}{ Gradient $\mathrm{F}$} \\
\hline $\begin{array}{l}\text { Time } \\
\text { [min] }\end{array}$ & $\begin{array}{c}\mathrm{MeOH} \\
{[\%]}\end{array}$ & $\begin{array}{l}\mathrm{H}_{2} \mathrm{O} \\
{[\%]}\end{array}$ & $\begin{array}{l}\text { Time } \\
\text { [min] }\end{array}$ & $\begin{array}{c}\mathrm{MeOH} \\
{[\%]}\end{array}$ & $\begin{array}{l}\mathrm{H}_{2} \mathbf{O} \\
{[\%]}\end{array}$ & $\begin{array}{l}\text { Time } \\
\text { [min] }\end{array}$ & $\begin{array}{c}\mathrm{MeOH} \\
{[\%]}\end{array}$ & $\begin{array}{l}\mathrm{H}_{2} \mathrm{O} \\
{[\%]}\end{array}$ \\
\hline 0.00 & 30.0 & 70.0 & 0.00 & 50.0 & 50.0 & 0.00 & 50.0 & 50.0 \\
\hline 4.00 & 30.0 & 70.0 & 4.00 & 50.0 & 50.0 & 4.00 & 50.0 & 50.0 \\
\hline 16.00 & 60.0 & 40.0 & 10.00 & 55.0 & 45.0 & 30.00 & 75.0 & 25.0 \\
\hline 19.00 & 80.0 & 20.0 & 12.00 & 75.0 & 25.0 & 50.00 & 75.0 & 25.0 \\
\hline 22.00 & 80.0 & 20.0 & 29.00 & 75.0 & 25.0 & & & \\
\hline
\end{tabular}

(R1) $\mathrm{OCN}-\mathrm{CH}_{2} \mathrm{CH}_{2}-\mathrm{NCO}+\mathrm{ROH} \stackrel{2 k_{1}}{\longrightarrow}$<smiles>O=CNCc1cccc(CN=O)c1</smiles>

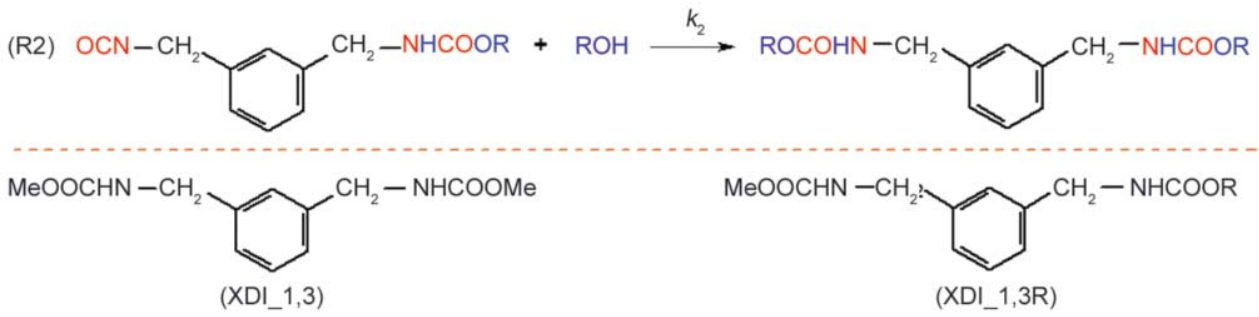

$\mathrm{ROOCHN}-\mathrm{CH}_{2}$ (XDI_1,3R)

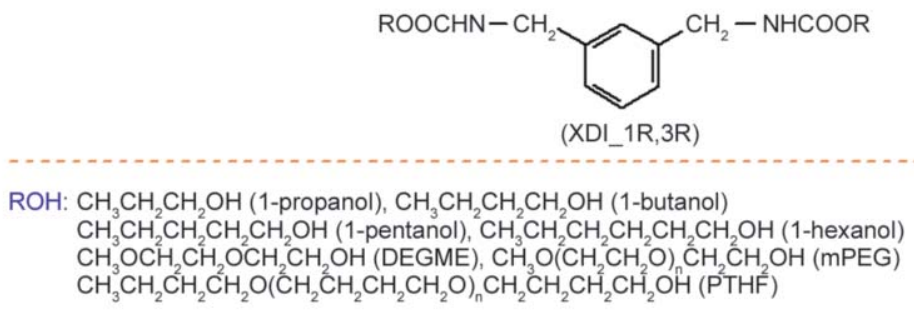

Figure 1. The products of the reaction of 1,3-XDI with alcohols and polyols together with the methanol-quenched reaction products. 
In order to calculate the relative concentrations of the products, i.e., the corresponding molar fractions $\left(X_{\mathrm{i}}\right)$, the peak areas obtained from HPLC-PDA measurements at $\lambda=210 \mathrm{~nm}$ were used similarly to those reported in our previous works $[17,18]$. The molar fractions of the unreacted ( $X_{\text {XDI } 1,3}$ ), the one-substituted ( $X_{\mathrm{XDI}} 1,3 \mathrm{R}$, one of two isocyanate groups has reacted) and the two-substituted ( $X_{\text {XDI_1R,3R }}$, both isocyanate groups has reacted) $1,3-\mathrm{XDI}$ come as given by Equations (1)-(3):

$$
\begin{aligned}
& X_{\text {XDI_1,3 }}=\frac{A_{\text {XDI_1,3 }}}{A_{\text {XDI_1,3 }}+A_{\text {XDI_1,3R }}+A_{\text {XDI_1R,3R }}} \\
& X_{\text {XDI_1,3R }}=\frac{A_{\text {XDI_1,3R }}}{A_{\text {XDI_1,3 }}+A_{\text {XD__1,3R }}+A_{\text {XDI_1R,3R }}} \\
& X_{\text {XDI } 1 \mathrm{R}, 3 \mathrm{R}}=1-X_{\text {XDI_1,3 }}-X_{\text {XDI_1,3R }}
\end{aligned}
$$

where $A_{\text {XDI_1,33 }}, A_{\text {XDI_1,3R }}$, and $A_{\text {XDI_1R,3R }}$ are the HPLC-UV peak areas of XDI_1,3, XDI_1,3R and XDI_1R,3R. Due to the very similar structures of the formed carbamates (urethanes), it was assumed in the derivation of Equations (1)-(3), that all these carbamates formed in reactions R1-R2 (Figure 1) have nearly equal response factors, i.e., equal absorption coefficients $\left(\varepsilon_{\text {XDI_1,3 }} \approx \varepsilon_{\text {XDI_1,3R }} \approx \varepsilon_{\text {XDI_1R,3R }}\right)$. The validity of this argument was independently confirmed by tracking the change of the sum of the peak areas during the reaction, and as a result, no trend in the variations of the summed peak areas was found.

In the case of pseudo-first-order reactions, the variations of the molar fractions of XDI_1,3, XDI_1,3R, and XDI_1R,3R with time can be described by Equations (4)-(6):

$$
\begin{aligned}
& X_{\text {XDI_ } 1,3}(t)=\mathrm{e}^{-2 \mathrm{k}_{1, \text { app }} \mathrm{t}} \\
& X_{\text {XDI } 1,3 \mathrm{R}}(t)=\frac{2 k_{1, \text { app }}}{k_{2, \text { app }}-2 k_{1, \text { app }}}\left(\mathrm{e}^{-2 \mathrm{k}_{1, \text { app }} \mathrm{t}}-\mathrm{e}^{-\mathrm{k}_{2, \text { app }} \mathrm{t}}\right) \\
& X_{\text {XDI_1R,3R }}(t)=1-X_{\text {XDI_1,3 }}(t)-X_{\text {XDI_1,3R }}(t)
\end{aligned}
$$

In order to obtain the pseudo-first-order rate coefficients, Equations (4)-(6) were fitted to the corresponding $X_{\mathrm{i}}$ versus time data using a Gauss-NewtonMarquardt procedure-based [19] home-made parameter estimation software written in Turbo Pascal 7.0.

\section{Results and discussion}

\subsection{The reaction of $1,3-\mathrm{XDI}$ with alcohols of varying alkyl chain lengths}

As shown in the Experimental section in order to obtain pseudo-first-order kinetics for the reaction of 1,3-XDI with alcohols, the alcohol components were employed in high molar excess to 1,3-XDI $\left([\text { Alcohol }]_{\mathrm{o}} /[1,3-\mathrm{XDI}]_{\mathrm{o}}=65\right)$. The HPLC-UV chromatogram and the variations of the product distributions with time for the reaction of 1,3-XDI with 1-propanol are shown in Figure 2, respectively.
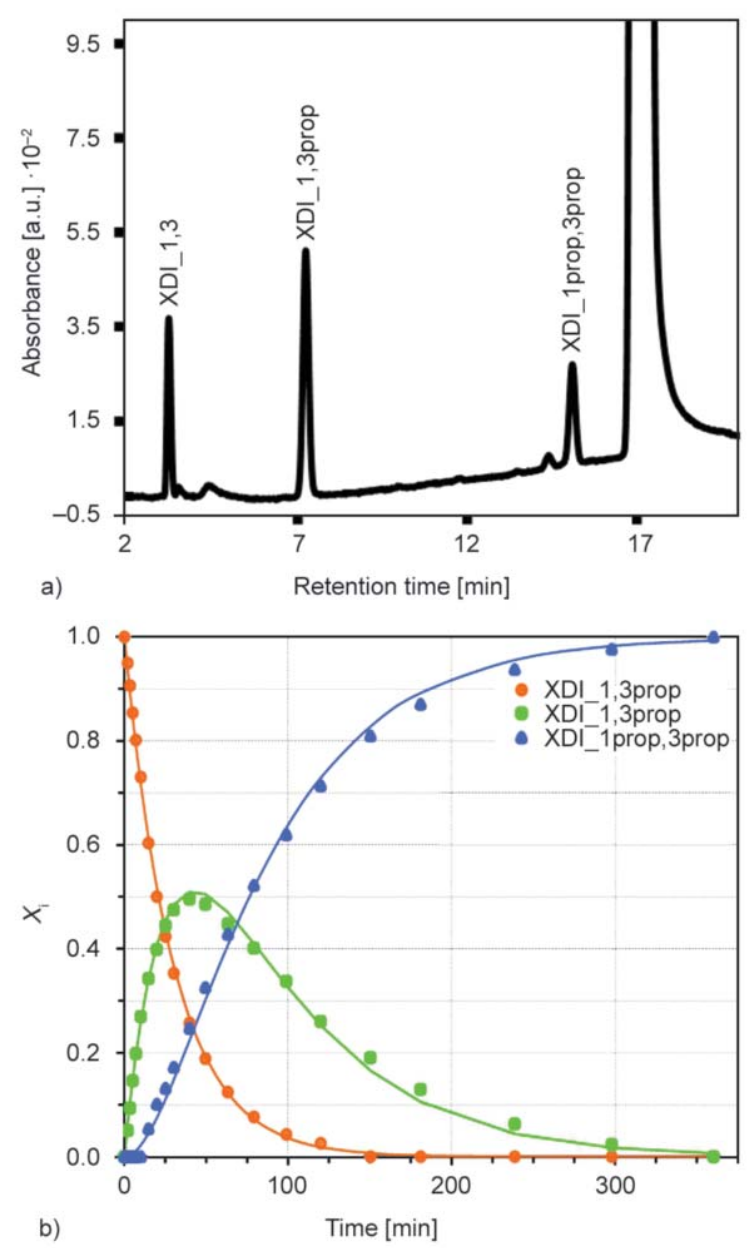

Figure 2. (a) HPLC-UV chromatogram of the 1,3-XDI-1propanol reaction recorded at $210 \mathrm{~nm}$ (reaction time: $20 \mathrm{~min}$, temperature: $80^{\circ} \mathrm{C}$; the intensive peak at 17 min corresponds to the toluene solvent). (b) The product distributions as a function of time for the reaction of 1,3-XDI with 1-propanol. Experimental conditions: $[1,3-\mathrm{XDI}]_{\mathrm{o}}=0.01 \mathrm{M}$, $[1 \text {-propanol }]_{\mathrm{o}}=0.65 \mathrm{M}, T=80^{\circ} \mathrm{C}$. The symbols represent the experimental molar fractions, while the solid lines denote the fitted curves by Equatios (4)-(6). The alcohol applied for the reaction was 1-propanol (denoted as $\mathrm{R}-\mathrm{OH}$ in Figure 1), the 'prop' denotes the abbreviation of the 1-propanol. 
As seen in Figure 2a, baseline separation of XDI_1,3, XDI_1,3prop, and XDI_1 prop,3prop can be achieved using the HPLC method presented in the Experimental section, thus making the quantification of these compounds possible. On the other hand, as shown in Figure $2 b$ Equations (4)-(6) adequately describe the product distribution and the kinetics is pseudo-firstorder with respect to the 1,3-XDI. Furthermore, it can also be inferred from Figure $2 b$ that molar fraction of XDI_1,3 decrease exponentially, and in par-

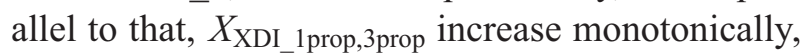
whereas the molar fraction of XDI_1,3prop shows a maximum value of nearly 0.5 . The maximum molar fraction of the XDI_1,3prop can theoretically be expected to be $k_{1, \text { app }} /\left(2 k_{2, \text { app }}\right)[17,18]$. Hence, the finding that the maximum value of $X_{\text {XDI_1,3R }}$ is close to 0.5 indicates that the value of $k_{1 \text {,app }}$ is nearly equal to that of $k_{2 \text {,app }}$, i.e., absence of any substitution effect. Similar plots of $X_{\mathrm{i}}$ against time to those presented in Figure $2 b$ were obtained for the urethane forming reactions with 1-butanol, 1-pentanol, and 1-hexanol. Hence, by fitting Equations (4)-(6) to the corresponding $X_{\mathrm{i}}$ versus time data the values of the apparent first-order rate coefficients $k_{1 \text {,app }}$ and $k_{2 \text {,app }}$ have been determined and these values obtained at $80^{\circ} \mathrm{C}$ are compiled in Table 2 .

As it turns out from the data of Table 2 the values of both $k_{1 \text {,app }}$ and $k_{2 \text {,app }}$ increase with the increasing chain length as going from 1-propanol to 1-hexanol and this tendency is also valid in the temperature range of $50-80^{\circ} \mathrm{C}$ as seen in Figure 3. The values of $k_{1 \text {,app }}$ and $k_{2 \text {,app }}$ are increased by 105 and $103 \%$ from 1-propanol to 1-hexanol at $80^{\circ} \mathrm{C}$, respectively. Furthermore, it is also evident from Table 2 that the ratio of $k_{1, \text { app }}$ and $k_{2 \text {,app }}$, is changing from 1.005 to 1.075 , which indicates that there is no significant substitution effect, i.e., the reactivity of the residual isocyanate group does not change after the first one has reacted.

Furthermore, it can also be recognized in Figure 3, there are only approximately two- to four-fold increase in the values of $k_{1 \text {,app }}$ (and this is also true for $k_{2, \text { app }}$, too) suggesting relative low activation energies

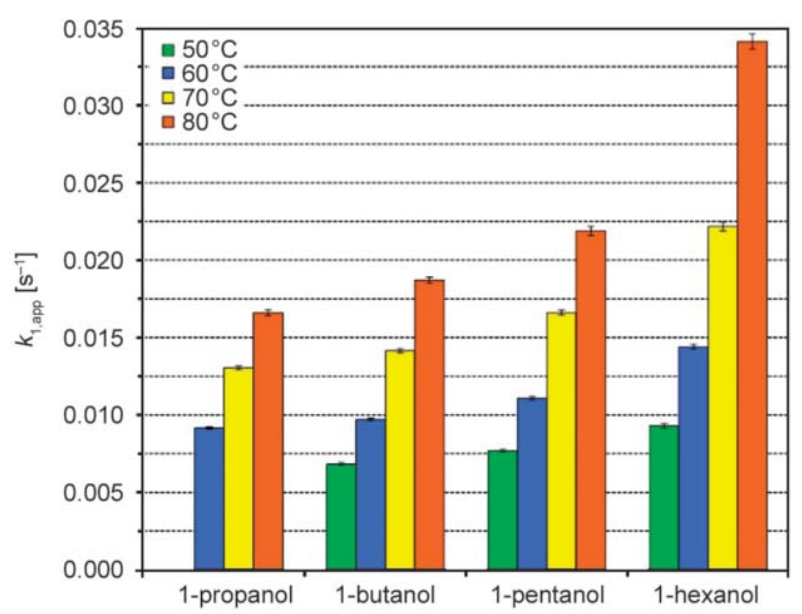

Figure 3. The change of the value of $k_{1 \text {,app }}$ with the length of the alkyl chain and the temperature. Experimental conditions: $[1,3-\mathrm{XDI}]_{\mathrm{o}}=0.01 \mathrm{M},[\text { Alcohol }]_{\mathrm{o}}=$ $0.65 \mathrm{M}$.

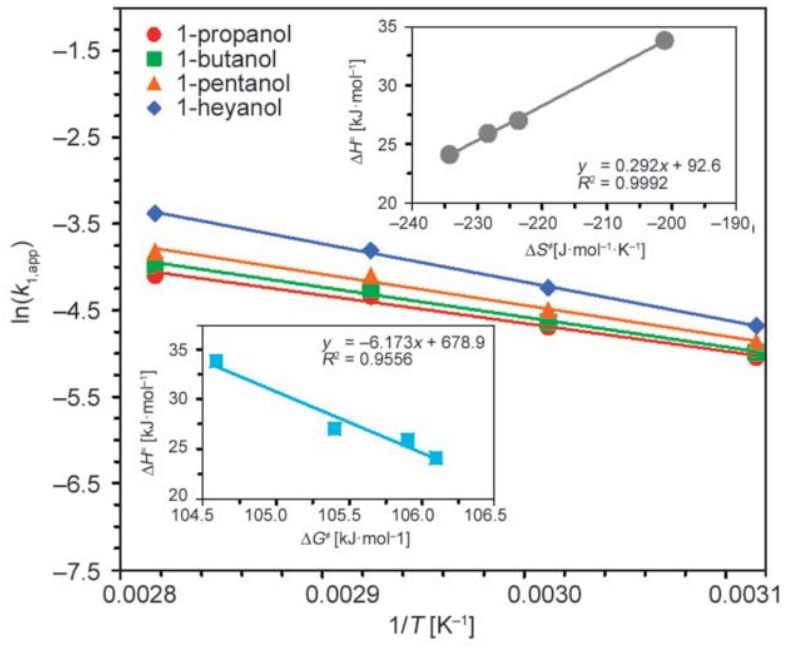

Figure 4. The Arrhenius-plots for the reactions of 1,3-XDI with 1-propanol, 1-butanol, 1-pentanol and 1-hexanol in the temperature range of $50-80^{\circ} \mathrm{C}$. Experimental conditions: see Figure 3 caption. Figure insets show the $\Delta H^{\neq}-\Delta \mathrm{S}^{\neq}$plot (upper) and the $\Delta H^{\ddagger}-\Delta G^{\ddagger}$ plot (lower). The activation enthalpy $\left(\Delta H^{\ddagger}\right)$ and the activation entropy $\left(\Delta S^{\ddagger}\right)$ were calculated as $\Delta H^{\neq}=E_{\mathrm{a}}-R<T>$, and $\Delta S^{\neq}=$ $R \ln \left(A h / k_{\mathrm{B}} /<T>\right)$, respectively, where $<T>$ is the average temperature, $h$ and $k_{\mathrm{B}}$ are the Planck and the Boltzmann constants, respectively. The pre-exponential factors $A$ were calculated from $A_{\text {app-s }}$ assuming a second order reaction between XDI and the alcohols.

Table 2. The apparent (pseudo first-order) rate coefficients for the reaction of 1,3-XDI with alcohols including 1-propanol, 1-butanol, 1-pentanol and 1-hexanol. Experimental conditions: $[1,3-\mathrm{XDI}]_{\mathrm{o}}=0.01 \mathrm{M},[\mathrm{Alcohol}]_{\mathrm{o}}=0.65 \mathrm{M}, T=80^{\circ} \mathrm{C}$.

\begin{tabular}{|ll|c|c|c|c|}
\hline \multicolumn{3}{|c|}{ Apparent rate coefficients } & \multicolumn{3}{|c|}{ Alcohol } \\
\cline { 3 - 6 } & & 1-propanol & 1-butanol & 1-pentanol & 1-hexanol \\
\hline$k_{1, \text { app }} \cdot 10^{2}$ & {$\left[\mathrm{~min}^{-1}\right]$} & $1.66 \pm 0.02$ & $1.87 \pm 0.02$ & $2.19 \pm 0.03$ & $3.41 \pm 0.05$ \\
\hline$k_{2, \text { app }} \cdot 10^{2}$ & {$\left[\mathrm{~min}^{-1}\right]$} & $1.57 \pm 0.02$ & $1.74 \pm 0.02$ & $2.18 \pm 0.03$ & $3.18 \pm 0.05$ \\
\hline
\end{tabular}


Table 3. The values of the natural logarithm of the apparent pre-exponential factors $\left(A_{1 \text {,app }}\right.$ and $\left.A_{2 \text {,app }}\right)$ and activation energies ( $E_{1 \text { a,app }}$ and $E_{2 \mathrm{a} \text { app }}$ ) for R1 and R2 reactions (see Figure 1.) of 1,3-XDI with alcohols. Experimental conditions: see Figure 3 caption.

\begin{tabular}{|l|c|c|c|c|}
\hline \multirow{2}{*}{ Apparent activation parameters } & \multicolumn{4}{c|}{ Alcohol } \\
\cline { 2 - 5 } & 1-propanol & 1-butanol & 1-pentanol & 1-hexanol \\
\hline $\ln \left(A_{1, \text { app }}\left[\mathrm{min}^{-1}\right]\right)$ & $5.05 \pm 0.76$ & $5.76 \pm 0.65$ & $6.33 \pm 0.79$ & $9.04 \pm 0.33$ \\
\hline$E_{1 \mathrm{a}, \mathrm{app} \quad[\mathrm{kJ} / \mathrm{mol}]}$ & $26.9 \pm 2.1$ & $28.7 \pm 1.8$ & $29.8 \pm 2.1$ & $36.6 \pm 0.9$ \\
\hline $\ln \left(A_{2, \mathrm{app}}\left[\mathrm{min}^{-1}\right]\right)$ & $4.55 \pm 0.68$ & $6.48 \pm 0.63$ & $7.53 \pm 0.76$ & $9.64 \pm 0.57$ \\
\hline$E_{2 \mathrm{a}, \mathrm{app} \quad[\mathrm{kJ} / \mathrm{mol}]}$ & $25.6 \pm 1.9$ & $31.0 \pm 1.8$ & $33.4 \pm 2.1$ & $38.6 \pm 1.6$ \\
\hline
\end{tabular}

for these urethane-forming reactions. To determine the corresponding apparent activation parameters, i.e., the apparent pre-exponential factor $\left(A_{\text {app }}\right)$ and the activation energy $\left(E_{\mathrm{a}, \mathrm{app}}\right)$, the Arrhenius-plots were constructed (Figure 4 ) and the determined apparent parameters from these plots are summarized in Table 3.

The data of Table 3 show that (i) the apparent activation energies for the process R1 and R2 (see Figure 1) are very close to each other and (ii) the apparent activation energies increase in the order of 1-propanol $<1$-butanol $<1$-pentanol $<1$-hexanol for both $\mathrm{R} 1$ and $\mathrm{R} 2$, while change in the values of $\ln A_{\text {app }}$ reveal an opposite trend resulting in increasing $k_{\text {app }}$ values as a function of chain length.

A tentative explanation for the increase of $k_{\text {app }}$ values with the length is that in non-polar media, like in toluene, the alcoholic $\mathrm{OH}$ group is more available for the reacting isocyanate group when the longer alkyl chains are more effectively solvated by the surrounding non-polar solvent molecules. Furthermore, a possible explanation for the increasing $E_{\mathrm{a} \text { app }}$ values in spite of the increasing kapp would be the 'enthalpy-entropy compensation effect' due to the propagation of unavoidable experimental errors [20, 21]. The strong correlation between $A_{\text {app }}$ and $E_{\text {a,app }}$ may hinder the chemical effects in the relatively narrow temperature range. Thus, in order to assess whether the observed trend is due to statistical or chemical effects, the $\Delta H^{\neq}-\Delta S^{\ddagger}$ and the $\Delta H^{+}-\Delta G^{\neq}$ plots were constructed as shown in Figure 4 insets. As it can be recognized, the $\Delta H^{+}-\Delta S^{\ddagger}$ plot indeed reveals (this is equivalent to the plot of $\log A-E_{\mathrm{a}}$ data) very strong correlation between $\Delta S^{\ddagger}$ and $\Delta H^{\ddagger}$ with a square of correlation coefficient $R^{2}=0.9992$, however, the $\Delta H^{\ddagger}-\Delta G^{\ddagger}$ plot with $R^{2}=0.9556$ show also a strong linear correlation suggesting the dominance of the chemical over the statistical effect [22]. Based on the results it can be concluded that $A_{\text {app }}$ has significant effect on the observed $k_{\text {app }}$ resulting in increasing $k_{\text {app }}$ values in spite of the increasing activation energies, i.e., the decrease in the exponential term with higher activation energy is overcompensated by the significant increase in the value of $A_{\text {app }}$. Although, this effect is rarely observed experimentally, but it is well-documented in the literature [23]. It is to be noted, however, that the apparent activation energies for the R1 and R2 processes of the MDI-1-butanol reaction (20.5 and $23.3 \mathrm{~kJ} / \mathrm{mol}$, respectively) are lower than those of the 1,3-XDI-1-butanol reaction [17]. Besides, the values of the apparent rate coefficients $k_{1 \text {,app }}$ and $k_{2 \text {,app }}$ of the reaction of MDI with 1-propanol at $80^{\circ} \mathrm{C}$ are much higher $(0.65$ and $0.41 \mathrm{~min}^{-1}$, respectively) [18] than those for the corresponding 1,3-XDI-1-propanol reaction (see the data of Table 2). These findings confirm again that the 1,3-XDI is less reactive towards alcohols than MDI, which is likely due to the presence of an additional $\mathrm{CH}_{2}$ group connected to the aromatic ring. Thus, this 'extended' system brings about a decrease in the positive partial charge on carbon atom of the $\mathrm{C}=\mathrm{O}$ group, thereby decreasing the reactivity of the isocyanate moiety.

In the next set of experiments, in order to elaborate the dependence of the apparent rate coefficients on the alcohol concentration, the 1-hexanol concentrations were varied in the range of 0.375 to $1.95 \mathrm{M}$. The product distributions for the 1,3-XDI versus 1-hexanol reaction obtained with 1-hexanol of $1.95 \mathrm{M}$ concentration are demonstrated in Figure $5 \mathrm{a}$, while the dependences of the apparent rate coefficients $k_{1, \text { app }}$ and $k_{2, \text { app }}$ on [1-hexanol] o are presented in Figure $5 \mathrm{~b}$. Figure 5 shows that the characteristics of the product distribution are similar to those obtained with lower alcohol concentration (Figure 5a) and that both $k_{1 \text {,app }}$ and $k_{2 \text {,app }}$ depend linearly on the alcohol concentration, supporting thus overall second-order kinetics for the reaction of 1,3-XDI with alcohols. 

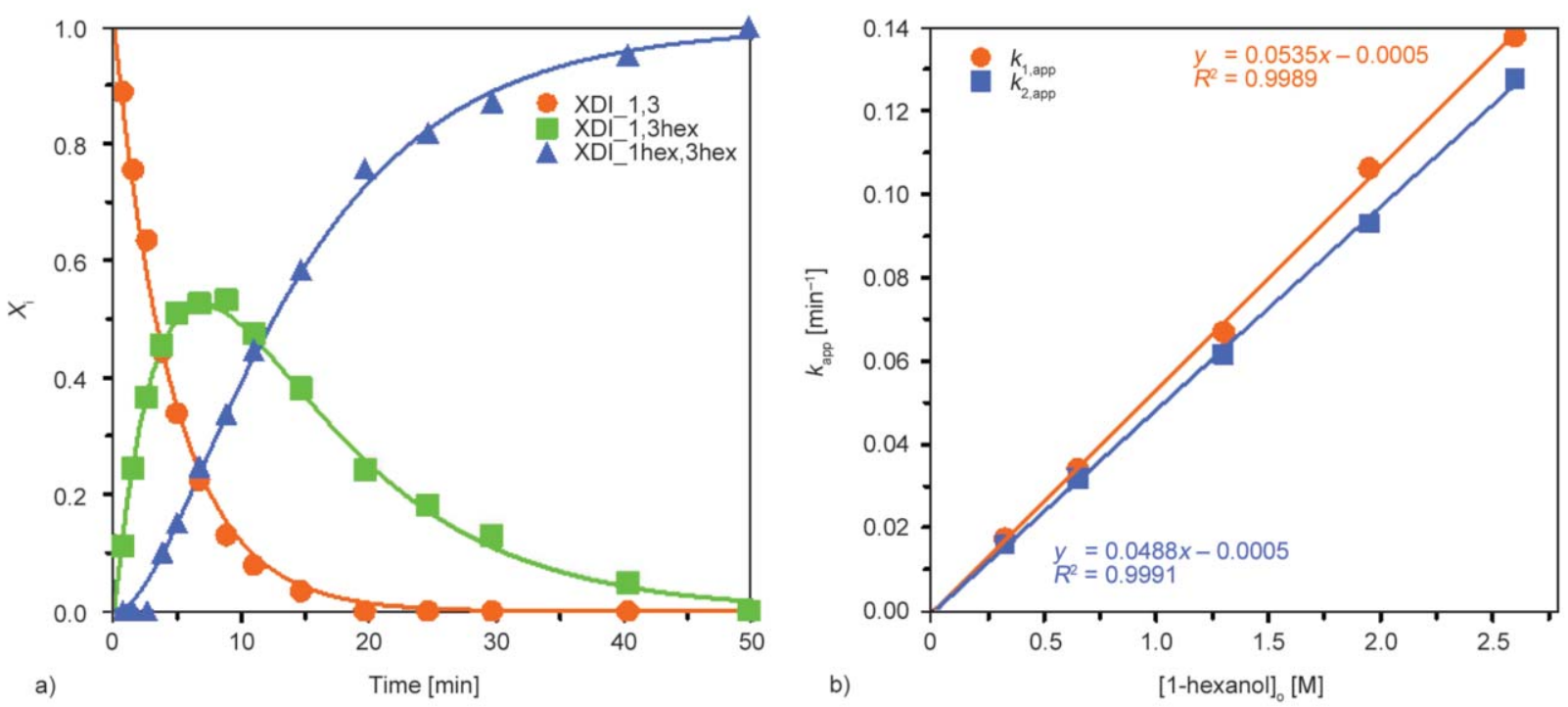

Figure 5. (a) Plots of the product distributions against time for the reaction of 1,3-XDI with 1-hexanol. Experimental conditions: $[1,3-\mathrm{XDI}]_{\mathrm{o}}=0.01 \mathrm{M},[1-\mathrm{hexanol}]_{\mathrm{o}}=1.95 \mathrm{M}, T=80^{\circ} \mathrm{C}$. The symbols represent the experimental molar fractions, while the solid lines denote the fitted curves by Equation (4)-(6). (b) The change of kapp values with the concentration of 1-hexanol. Experimental conditions: $[1,3-\mathrm{XDI}]_{\mathrm{o}}=0.01 \mathrm{M}, T=80^{\circ} \mathrm{C}$. The 'hex' in the legend denotes the abbreviation of the 1-hexanol.

\subsection{The reaction between $1,3-X D I$ and metoxylated PEG (mPEG)}

Next, we focus on the following tasks: (i) The application of the simple model presented in Figure 1 for the description of the product distributions formed in the reaction of 1,3-XDI with polymer polyols like PEG and (ii) prediction of such product distributions from those obtained in the corresponding reaction of a simple compound mimicking the polymer polyol chain-end. To perform these tasks, DEGME, which mimic completely the chain and the chain-end of PEGs was employed for these kinetic experiments. The product distributions obtained in the 1,3-XDIDEGME reaction together with the fitted curves are shown in Figure 6a.

For the values of $k_{1 \text {,app }}$ and $k_{2, \text { app }}(2.64 \pm 0.03) \cdot 10^{-3}$ and $(2.45 \pm 0.03) \cdot 10^{-3} \mathrm{~min}^{-1}$ were deduced from the fitting, respectively. It is worth mentioning that these
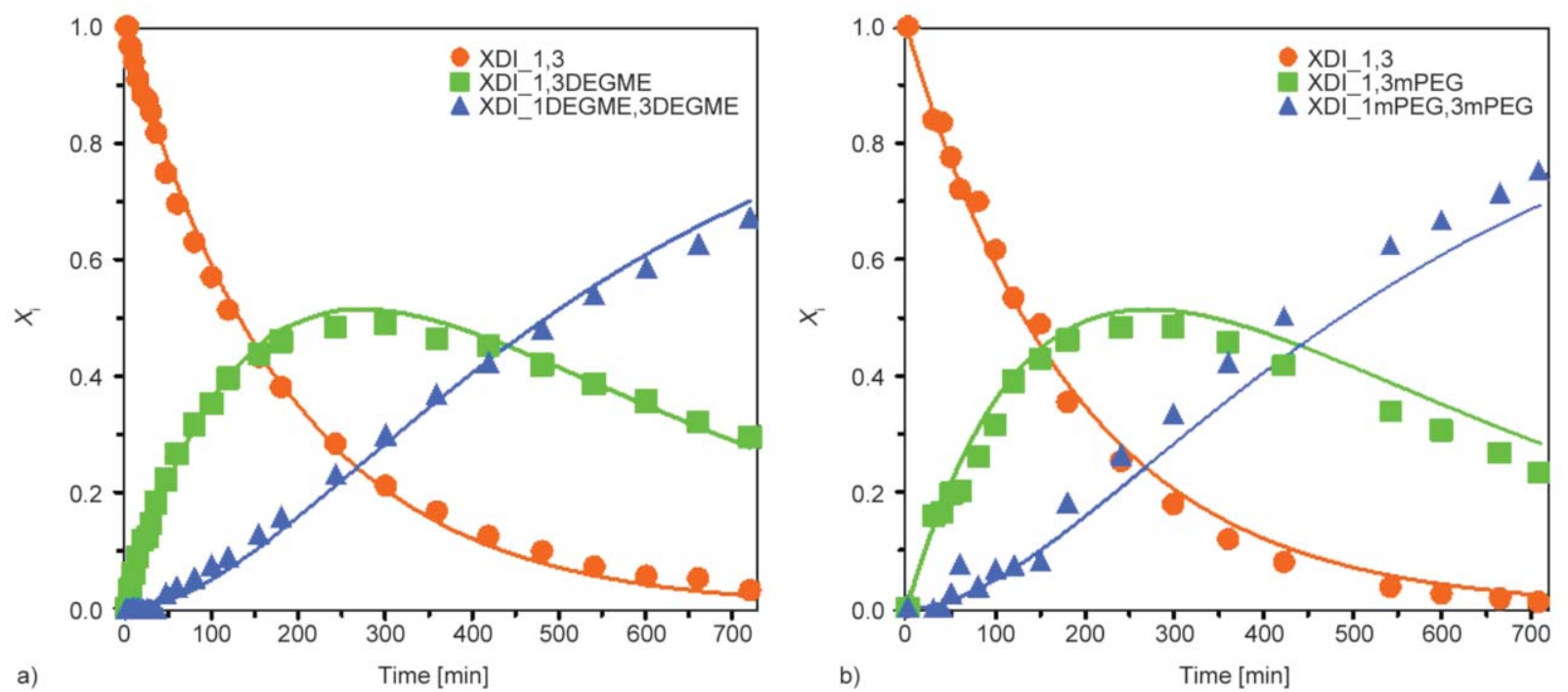

Figure 6. (a) The dependence of the product distributions on the reaction time for the reaction of 1,3-XDI with DEGME and (b) with mPEG. Experimental conditions: $[1,3-\mathrm{XDI}]_{\mathrm{o}}=0.01 \mathrm{M},[\mathrm{DEGME}]_{\mathrm{o}}=0.65 \mathrm{M},[\mathrm{mPEG}]_{\mathrm{o}}=0.65 \mathrm{M}, T=$ $80^{\circ} \mathrm{C}$. The symbols in Figure 6a. and Figure $6 \mathrm{~b}$ represent the experimental molar fractions. The solid lines in Figure 6a stand for the fitted curves by Equation (4)-(6), while solid lines in Figure 6b. denote the product distributions calculated with the fitted apparent rate coefficients obtained from the 1,3-XDI versus DEGME reaction (Figure 6b). 
apparent rate coefficients are significantly lower than those for the alkyl chain alcohols (see Table 2). This finding is in line with our previous results obtained for similar urethane forming reaction with MDI and TDI [17]. The lower reactivity of DEGME towards isocyanates, due to the inductive effect of the ether oxygen atom, may be attributed to a decreased partial negative charge on the reacting $\mathrm{OH}$ group of DEGME.

Figure $6 \mathrm{~b}$ demonstrates the product distributions in the reaction of 1,3-XDI with the monometoxylated PEG under the same experimental conditions as those were applied for the 1,3-XDI versus DEGME reaction. It can be surmised from the comparison of Figure 6a and Figure 6b, that two product distributions are rather similar. In addition, using the apparent rate coefficients obtained from the kinetics of the 1,3-XDI-DEGME reaction for the 1,3-XDI-PEG reaction, the product distribution curves calculated with these apparent rate coefficients match well the experimental ones. Hence, the prediction of the product distributions for a polymer polyol system using the kinetic data of a much simpler system that can mimic the reacting polymer chain-end seems to be an appropriate approximation, which is of practical importance.

\subsection{The reaction between $1,3-\mathrm{XDI}$ and polytetrahyrofuran (PTHF)}

Polytetrahydrofuran represents an important raw material in the polyurethane industry used for manufacturing of various elastomers [24]. Therefore, in this section, we address its reaction with 1,3-XDI. In these experiments, low molecular weight PTHF $\left(M_{\mathrm{n}}=\right.$ $250 \mathrm{~g} / \mathrm{mol}$ ) was used, which contained two reacting $\mathrm{OH}$ end-groups per chain. The presence of the two reactive $\mathrm{OH}$ end-groups may be expected to complicate the kinetics due to the potential formation of product with two isocyanate end-groups. The formation of such products was excluded in the case of mPEG in which one of the two $\mathrm{OH}$ groups was 'inactivated' by metoxylation. A similar approach, however, was not feasible in the case of PTHF. However, we have demonstrated earlier that applying high molar excess of polyol to diisocyanate the probability of formation of such side products is very low; thus, its concentration can be neglected with respect to those of the other products [25]. The reaction of 1,3-XDI with the PTHF yielded products that were each separated by HPLC according to their total number of repeat units of PTHF. First, for the sake of simplicity, these individual, separated peaks were correspondingly summed to get molar fractions of XDI_1,3, XDI_1,3PTHF, and XDI_1PTHF,3PTHF. (Note that in the case of $\mathrm{mPEG}$ where the molecular weight was higher, HPLC was unable to separate the products according to the number of repeat units, thus all individual oligomers belonging to a given type of products eluted as one peak). In Figure 7a variations of the molar fractions of XDI_1,3, XDI_1,3PTHF and XDI_1PTHF,3PTHF with time are plotted.

As seen in Figure 7a the fitted curves match well the experimental data and from the fitting for $k_{1, \text { app }}$ and $k_{2, \text { app }}$ values were found to be $(1.13 \pm 0.01) \cdot 10^{-2}$ and $(1.28 \pm 0.01) \cdot 10^{-2} \mathrm{~min}^{-1}$, respectively.

We also attemptrd to calculate the product distributions for all individual oligomers. The variations of the molar fraction of 1,3-XDI with time can also be described using Equation (4), while the change of the molar fractions for the one- $\left(X_{\mathrm{M}_{\mathrm{i}}}\right)$ and the twosubstituted $\left(X_{\mathrm{D}_{\mathrm{i}+\mathrm{j}}}\right)$ oligomers as a function of time can be given by Equations (7) and (8) providing that the rate coefficients are independent of the chain length, and the reaction rate depend on the first power of the alcohol concentration:

$X_{\mathrm{M}_{\mathrm{i}}}(t)=\frac{2 \kappa_{\mathrm{i}} k_{1, \text { app }}}{k_{2, \text { app }}-2 k_{1, \text { app }}}\left(\mathrm{e}^{-2 \mathrm{k}_{1, \text { app }} \mathrm{t}}-\mathrm{e}^{-\mathrm{k}_{2, \text { app }} \mathrm{t}}\right)$

where $5 \geq i \geq 2$

$$
\begin{aligned}
& X_{\mathrm{D}_{\mathrm{i}+\mathrm{j}}}(t)=\frac{\kappa_{\mathrm{i}} \kappa_{\mathrm{j}} k_{1, \text { app }} k_{2, \text { app }}}{k_{2, \text { app }}-2 k_{1, \text { app }}} \\
& \cdot\left[\frac{1}{k_{1, \text { app }}}\left(1-\mathrm{e}^{-2 \mathrm{k}_{1, \text { app }} \mathrm{t}}\right)-\frac{2}{k_{2, \text { app }}}\left(1-\mathrm{e}^{-\mathrm{k}_{2, \text { app }} \mathrm{t}}\right)\right]
\end{aligned}
$$

where $9 \geq i+j \geq 4$

In Equations (7) and (8) $\kappa_{\mathrm{i}}$ represents the molar fractions of the oligomers with a number of repeat units $i$ present in the sample. Thus, the description of the variation of the individual oligomers in the starting PTHF sample with time requires additional knowledge on the distribution of the oligomers as a function of the number of repeat units. Determination of such distribution, moreover, is not a straightforward task. For example, mass spectrometric (MS) methods such as electrospray ionization (ESI) may give some information on the chain distribution, it is expected, however, that such distribution may suffer from non-equal ionization efficiency for all oligomers present in the sample and/or mass discrimination 

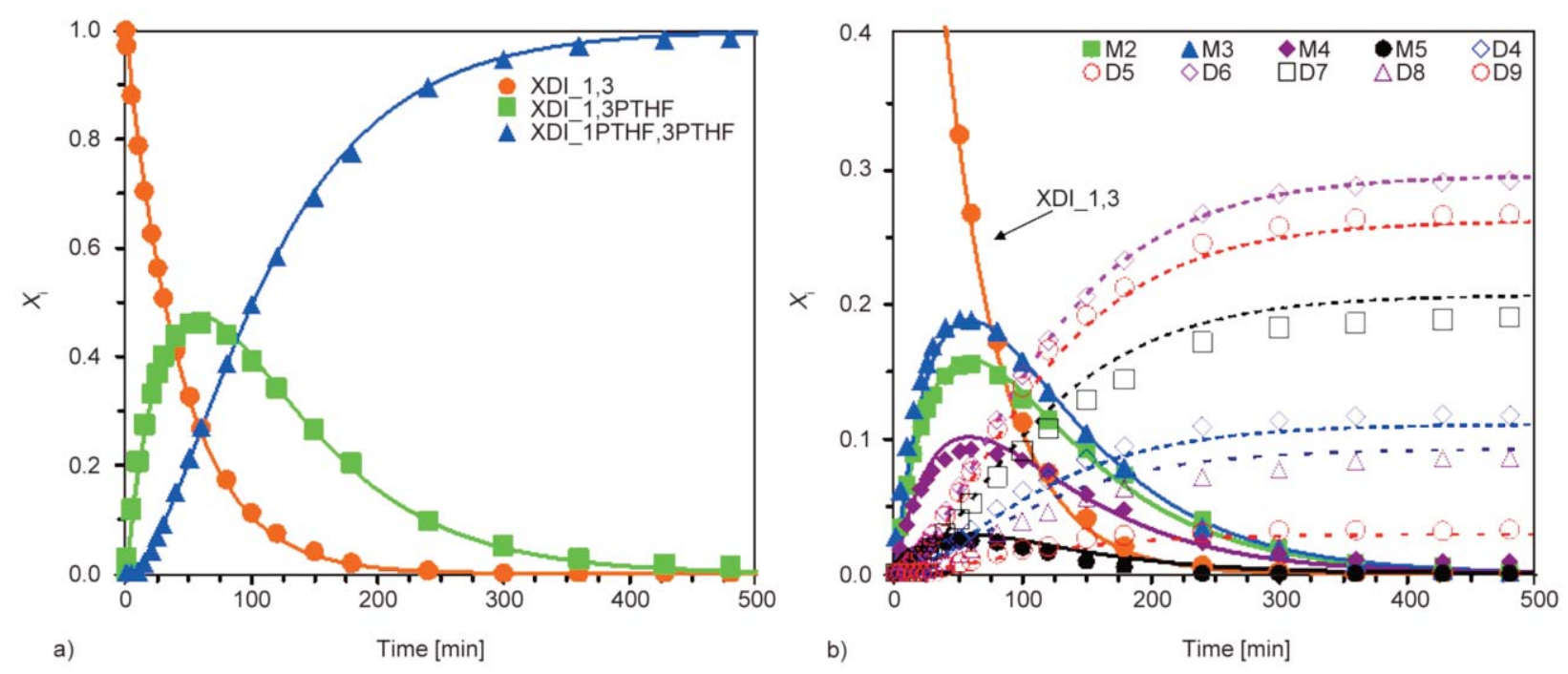

Figure 7. (a) Plots of the product distributions against time for the reaction between 1,3-XDI and PTHF using the sum of the oligomer HPLC peak area and (b) using the individual oligomer HPLC peak area. Experimental conditions: [1,3$\mathrm{XDI}]_{\mathrm{o}}=0.01 \mathrm{M},[\mathrm{PTHF}]_{\mathrm{o}}=0.32 \mathrm{M}^{*}, T=80^{\circ} \mathrm{C}$. The symbols in Figure $7 \mathrm{a}$ and Figure $7 \mathrm{~b}$ represent the experimental molar fractions. The solid lines in Figure 7a stand for the fitted curves by Equations (4)-(6), while the solid and the dashed lines in Figure 7b denote the fitted product distributions by Equations (7)-(10) and Equations (11)-(14), respectively. M2, M3, M4 and M5 are the products XDI_1,3PTHF in which the attached PTHF oligomer has a number of repeat units 2, 3, 4 and 5, respectively. D4, D5, D6, D7, D8 and D9 means the products XDI_1PTHF,3PTHF in which the sum of the number of units of all PTHF attached is 4, 5, 6, 7, 8 and 9, respectively.

${ }^{*}$ Note that PTHF contains two OH groups per molecule, thus, to obtain the same concentration of $\mathrm{OH}$ group as those for the other alcohols and mPEG, its concentration has to be halved.

effect caused by the MS detection system. Thus, we decided to choose another, appropriate method, which gives the most reliable results based on the reaction of PTHF with a high excess of phenyl isocyanate. In this way, all PTHF chains were reacted to form urethane, which was then separated by HPLC, and the individual oligomer chains with urethane endgroups were detected by UV. Since it is highly expected that the chain lengths do not influence the molar absorbance of the urethane end-group, the relative ratio of the peak area provides the chain distribution in the original sample. Using this approach, we determined that the PTHF sample consisted of oligomers with number of repeat units $n=2,3,4$ and 5 , and the molar fractions of these oligomers $\left(\kappa_{\mathrm{i}}\right)$ were found to be $0.33,0.39,0.21$ and 0.07 , respectively. It should be noted that the PTHF sample contained oligomers with $n=1$ and 6 ; however, their molar fractions were very low $(<0.02)$; therefore, they were not included in the calculations. Furthermore, it is important to note that in the calculations when using Equation (8) it should be taken into account that there may be several routes to form the given two-substituted products. For example, if we consider the formation a two-substituted product with $n=6$, it could be formed from the reaction of one-substituted derivative with $n=3$ and a PTHF chain with $n=3$, and the reaction of one-substituted derivative with $n=2$ and a PTHF chain with $n=4$, and the reaction of one-substituted derivative with $n=4$ and a PTHF chain with $n=2$. Thus, the fits of Equation (4) and Equations (7) and (8) to the experimental data are good as demonstrated in Figure $7 \mathrm{~b}$. The values of $k_{1 \text {,app }}$ and $k_{2 \text {,app }}$ were found to be $(1.13 \pm 0.01) \cdot 10^{-2}$ and $(1.25 \pm 0.02) \cdot 10^{-2} \mathrm{~min}^{-1}$, respectively, which are in line with those obtained by fitting to the summed product distributions. Besides, this good agreement also confirms that the rate coefficients do not depend significantly on the polymer chain length.

Interestingly, the obtained $k_{\text {app }}$ values are lower than those obtained for the alkyl chain alcohols (see Table 2), supporting again the fact that the presence of an oxygen atom decreases the reactivity of the reacting $\mathrm{OH}$ group towards the isocyanate.

\subsection{Proposed mechanism for the reaction of 1,3-XDI with alcohols and polyols}

Based on our investigations it seems likely that the reaction of 1,3-XDI with alcohols proceeds according to overall second-order kinetics in which both the two reactants, the isocyanate, and the alcohol is 


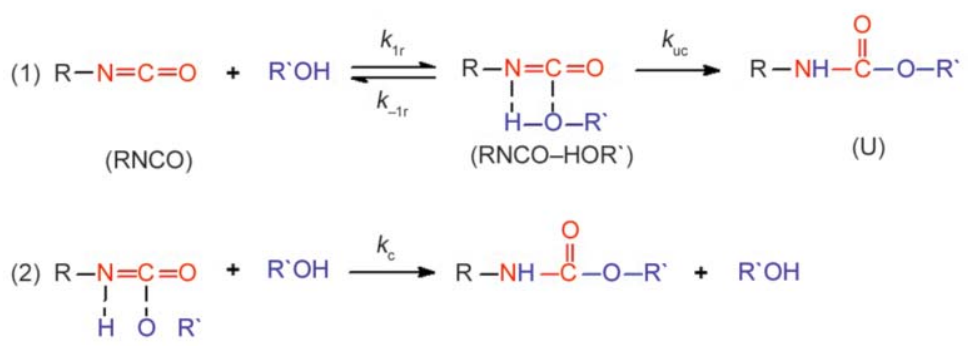

Figure 8. Proposed mechanism for the reaction between 1,3-XDI and alcohols.

first-order with respect to its concentration. Although the second-order kinetics may suggest a straightforward mechanism in which the product is formed in one reaction step (bimolecular mechanism), moreover, many studies on this topic prefer a more complex reaction mechanism. In keeping with these studies we propose a general mechanism, which has been also employed for the interpretation of the complex kinetics found in the reaction of 4,4'-MDI and 2,4TDI with alcohols [17].

According to Figure 8, followed by a nuchleophilic attack, an adduct RNCO-HOR' is formed in a reversible reaction, which yields the product urethane (U) in an uncatalyzed route (reaction 1) and/or this adduct can further react with the alcohol to form the product. It is to be noted that this second route is a self-catalyzed reaction by the alcohol. According to the proposed mechanism (Figure 8), for the rate of formation of urethane $(\mathrm{U})$ the following rate-equation can be derived (Equation (9)):

$$
\frac{\mathrm{d}[\mathrm{U}]}{\mathrm{d} t}=\frac{k_{1 \mathrm{r}}[\mathrm{RNCO}]\left[\mathrm{R}^{\prime} \mathrm{OH}\right]}{k_{-1 \mathrm{r}}+k_{\mathrm{uc}}+k_{\mathrm{c}}\left[\mathrm{R}^{\prime} \mathrm{OH}\right]}\left(k_{\mathrm{uc}}+k_{\mathrm{c}}\left[\mathrm{R}^{\prime} \mathrm{OH}\right]\right)
$$

If $k_{-1 \mathrm{r}}+k_{\mathrm{uc}} \ll k_{\mathrm{c}}\left[\mathrm{R}^{\prime} \mathrm{OH}\right]$ and $k_{\mathrm{uc}} \ll k_{\mathrm{c}}\left[\mathrm{R}^{\prime} \mathrm{OH}\right]$ are valid then Equation (9) reduces to Equation (10), which describes second-order kinetics, and this is in line with our observations for the 1,3-XDI-alcohol system:

$$
\frac{\mathrm{d}[\mathrm{U}]}{\mathrm{d} t}=k_{1 \mathrm{r}}[\mathrm{RNCO}]\left[\mathrm{R}^{\prime} \mathrm{OH}\right]
$$

Besides, as we highlighted before, the $4,4^{\prime}$-MDI and 2,4-TDI alcohol system behave differently form the present system under the same experimental conditions. The rate-equation for the 4,4'-MDI and 2,4Equation (11) [17]:

$$
\frac{\mathrm{d}[\mathrm{U}]}{\mathrm{d} t}=\frac{a\left[\mathrm{RNCO}^{\prime}\left[\mathrm{R}^{\prime} \mathrm{OH}\right]^{2}\right.}{b+\left[\mathrm{R}^{\prime} \mathrm{OH}\right]}
$$

where $a=k_{1 \mathrm{r}}$ and $b=k_{-1 \mathrm{r}} / k_{\mathrm{c}}$ and $k_{\mathrm{uc}} \ll k_{\mathrm{c}}\left[\mathrm{R}^{\prime} \mathrm{OH}\right]$.
It is accepted that the value of $k_{-1 \mathrm{r}}$ decreases with respect to that of $k_{\mathrm{c}}\left[\mathrm{R}^{\prime} \mathrm{OH}\right]$ as going from aromatic to aliphatic isocyanates [26]. Indeed, most probably, the lower value of $k_{-1 \mathrm{r}}$, due to the relation of $b \ll$ [ $\left.\mathrm{R}^{\prime} \mathrm{OH}\right]$ in the case of 1,3-XDI-alcohol reaction makes Equation (11) first-order with respect to alcohol concentration.

Besides, the mechanism shown in Figure 8 is also capable of describing the more complex kinetics of such systems.

\section{Conclusions}

The kinetics of the reaction of 1,3-XDI and alcohols of varying alkyl chain lengths and polyols was investigated in high molar excess of alcohols to isocyanate in order to obtain pseudo-first-order dependences. These kinetic investigations revealed that both apparent rate coefficients $k_{1 \text {,app }}$ and $k_{2 \text {,app }}$ increased with the increasing chain lengths of the alcohols. This finding was explained as better solvation of the longer chains in toluene making the reacting $\mathrm{OH}$ group more available for the isocyanate groups. The activation parameters for these reactions were determined and interpreted in terms of statistical and chemical effects. It was also demonstrated that the product distributions in a polymer polyol-isocyanate reaction can be predicted effectively using the rate coefficients obtained from a much simplier system that can mimic the corresponding polymer polyol-isocyanate reaction. The application of this approach is of benefit from practical point of view, too. It was also shown that the products formed in a reaction of a low molecular weight polytetrahydrofuran with 1,3-XDI can be separated by HPLC according to the number of repeat units of PTHF and the apparent rate coefficients are independent of the chain lengths. Furthermore, based on our present and previous studies we proposed a mechanism for the reaction of 1,3-XDI with alcohols, which involves a selfcatalysis by alcohol. In addition, in order to support 
these findings theoretically as well, high-level quantum chemical calculations are planned to be carried out.

\section{Acknowledgements}

The work was supported by grant No. FK-128783 from National Research, Development and Innovation Office (NKFI). The work reported here was also supported by GINOP-2.3.2-15-2016-00041 project, co-financed by the European Union and the European Regional Development Fund.

\section{References}

[1] Kausar A.: Polyurethane composite foams in high-performance applications: A review. Polymer-Plastics Technology and Engineering, 57, 346-369 (2018). https://doi.org/10.1080/03602559.2017.1329433

[2] Saleh S., Yunus N. Z. M., Ahmad K., Ali N.: Improving the strength of weak soil using polyurethane grouts: A review. Construction and Building Materials, 202, 738 752 (2019).

https://doi.org/10.1016/j.conbuildmat.2019.01.048

[3] Bhattacharyya A., Mukherjee, D., Mishra R., Kundu P. P.: Preparation of polyurethane-alginate/chitosan core shell nanoparticles for the purpose of oral insulin delivery. European Polymer Journal, 92, 294-313 (2017). https://doi.org/10.1016/j.eurpolymj.2017.05.015

[4] Jung S. Y., Lee S. J., Kim H. Y., Park H. S., Wang Z., Kim H. J., Yoo J. J., Chung S. M., Kim H. S.: 3D printed polyurethane prosthesis for partial tracheal reconstruction: A pilot animal study. Biofabrication, 8, 045015/1-045015/10 (2016). https://doi.org/10.1088/1758-5090/8/4/045015

[5] Leng J., Lan X., Liu Y., Du S.: Shape-memory polymers and their composites: Stimulus methods and applications. Progress in Materials Science, 56, 1077 1135 (2011). https://doi.org/10.1016/j.pmatsci.2011.03.001

[6] Lakatos Cs., Czifrák K., Papp R., Karger-Kocsis J., Zsuga M., Kéki S.: Segmented linear shape memory polyurethanes with thermoreversible Diels-Alder coupling: Effects of polycaprolactone molecular weight and diisocyanate type. Express Polymer Letters, 10, 324 336 (2016).

https://doi.org/10.3144/expresspolymlett.2016.30

[7] Platonova E. O., Vlasov E., Pavlov A. Kireynov A., Nelyub V., Polezhaev A. V.: Self-healing polyurethane based on a difuranic monomer from biorenewable source. Journal of Applied Polymer Science, 136, 47869/1-47869/8 (2019). https://doi.org/10.1002/app.47869

[8] Sonnenschein M. F.: Polyurethanes: Science, technology, markets, and trends. Wiley, Hoboken (2015).
[9] Król P.: Synthesis methods, chemical structures and phase structures of linear polyurethanes. properties and applications of linear polyurethanes in polyurethane elastomers, copolymers and ionomers. Progress in Materials Science, 52, 915-1015 (2007).

https://doi.org/10.1016/j.pmatsci.2006.11.001

[10] Rumao L. P., Frisch K. C.: Thermal degradation of polyurethanes based on xylylene diisocyanates. Journal of Polymer Science Part A1: Polymer Chemistry, 10, 1499-1509 (1972).

https://doi.org/10.1002/pol.1972.150100518

[11] Yamazaki A., Inagaki K.: Laminated film. U.S. Patent 20190054724A1, USA (2017).

[12] Shin J., Han H. H., Hong S. M., Kim S. M.: Xylylene diisocyanate composition with improved stability and reactivity and optical lens using the same. U.S. Patent 20180334428, USA (2018).

[13] Uchida T., Kouda C., Dinh H. Y.: Laminate, food packaging material, and method for producing laminate. U.S. Patent 10434751B2, USA (2018).

[14] Mitsui Chemical: $360^{\circ}$ business innovation. Annual Report (2016).

[15] Matuszak M. L., Frisch K. C., Reegen S. L.: Hydrolysis of linear polyurethanes and model monocarbamates. Journal of Polymer Science: Polymer Chemistry Edition, 11, 1683-1690 (1973).

https://doi.org/10.1002/pol.1973.170110716

[16] Ferstandig L. L., Scherrer R. A.: Mechanism of isocyanate reactions with ethanol. Journal of the American Chemical Society, 81, 4838-4842 (1959).

https://doi.org/10.1021/ja01527a022

[17] Nagy T., Antal B., Czifrák K., Papp I., Karger-Kocsis J., Zsuga M., Kéki S.: New insight into the kinetics of diisocyanate-alcohol reactions by high-performance liquid chromatography and mass spectrometry. Journal of Applied Polymer Science, 132, 42127/1-42127/9 (2015). https://doi.org/10.1002/app.42127

[18] Nagy L., Nagy T., Kuki Á., Purgel M., Zsuga M., Kéki S.: Kinetics of uncatalyzed reactions of 2,4'- and 4,4'diphenylmethane-diisocyanate with primary and secondary alcohols. International Journal of Chemical Kinetics, 49, 643-655 (2017).

https://doi.org/10.1002/kin.21104

[19] Marquardt D. W.: An algorithm for least-squares estimation of nonlinear parameters. Journal of the Society for Industrial and Applied Mathematics, 11, 431-441 (1963).

https://doi.org/10.1137/0111030

[20] Krug R. R., Hunter W. G., Grieger R. A.: Enthalpy-entropy compensation. 1. Some fundamental statistical problems associated with the analysis of van't Hoff and Arrhenius data. Journal of Physical Chemistry, 80, 2335-2341 (1976). https://doi.org/10.1021/j100562a006 
[21] Barrie P. J.: The mathematical origins of the kinetic compensation effect: 1 . The effect of random experimental errors. Chemical Physics Physical Chemistry, 14, 318-326 (2012). https://doi.org/10.1039/C1CP22666E

[22] Krug R. R., Hunter W. G., Grieger R. A.: Enthalpy-entropy compensation. 2. Separation of the chemical from the statistical effect. Journal of Physical Chemistry, 80, 2341-2351 (1976).

https://doi.org/10.1021/j100562a007

[23] Lente G.: Deterministic kinetics in chemistry and systems biology. Springer, New York (2015).
[24] Dreyfuss P.: Polytetrahydrofurans. in 'Handbook of elastomers' (eds.: Bhowmick A. K., Stephens L. H.) Marcel Dekker, New York, 723-734 (2000).

[25] Nagy L., Vadkerti B., Batta Gy., Fehér P. P., Zsuga M., Kéki S.: Eight out of eight: A detailed kinetic study on the reactivities of the eight hydroxyl groups of sucrose with phenyl isocyanate. New Journal of Chemistry, 43, 15316-15325 (2019).

https://doi.org/10.1039/C9NJ03569A

[26] Król P.: Linear polyurethanes: Synthesis methods, chemical structures, properties and applications. Leiden, Boston (2008). 